\title{
Budd-Chiari syndrome as a complication of paroxysmal nocturnal haemoglobinuria
}

\author{
A. R. HoRLeR \\ M.D., F.R.C.P. \\ Consultant Physician
}

\author{
M. T. SHAW* \\ M.B., M.R.C.P., D.C.H. \\ Medical Registrar
}

\author{
R. B. THOMPSON \\ M.D., F.R.C.P. \\ Consultant Physician
}

ThrombophleBitis is a frequent complication of paroxysmal nocturnal haemoglobinuria and thromboembolism is a recognized cause of death (Crosby, 1953). The occurrence of thromboses in the hepatic and portal venous radicles at autopsy has been described by Bergmark (1931), Scott, Robb-Smith \& Scaven (1938), Ham \& Horack (1941), Ellenhorn et al. (1951), Merliss (1952) and Heitzman, Campbell \& Stefanini (1953). The development of the BuddChiari syndrome in a patient with paroxysmal nocturnal haemoglobinuria has been reported by Refvem \& Ytrehus (1959) and so far as we are aware, this is the only published account of this clinical association. Two patients investigated in the Royal Victoria Infirmary, Newcastle upon Tyne, were each found to be suffering simultaneously from these two conditions.

\section{Case reports}

Patient No. 1

A 31-year-old coal-miner was admitted to hospital as an emergency on 10 May, 1959, complaining of passing dark-coloured urine. Four years earlier, after a haemorrhoidectomy, he had been found to be anaemic and was transfused. During the previous year he had complained of fatigue, weakness and lightheadedness and was treated with intramuscular iron-dextran for anaemia. Six months before admission he had noticed on two occasions that his urine was red. Three days before admission he again began to pass dark red, almost black urine; the colour was most marked early in the morning on rising but cleared to some extent later in the day.

*Present address: The Royal Postgraduate Medical School, London, W.12.
Examination revealed a pale, slightly jaundiced man. There was no enlargement of the lymphnodes or of the liver and spleen.

Investigations: Blood. $\mathrm{Hb} 8.9 \mathrm{~g} / 100 \mathrm{ml}, \mathrm{RBC} 3.25$ million $/ \mathrm{mm}^{3}$, reticulocytes $5 \%$, PCV $28 \%$ MCV $89 \mu^{3}$, MCHC $32 \%$, platelets $450,000 / \mathrm{mm}^{3}$, WBC $2000 / \mathrm{mm}^{3}$, neutrophils $57 \%$, eosinophils $4 \%$, lymphocytes $29 \%$, monocytes $10 \%$. Film: red cells slightly hypochromic with anisocytosis and polychromasia.

Spectroscopic examination of the plasma revealed haemoglobin and methaemalbumen. The urine, which was almost black, contained haemoglobin and a large amount of haemosiderin; there was a slight excess of urobilin but bilirubin and bile salts were absent.

The Ham test and the Hegglin \& Maier test were positive. Coombs' test, Donath-Landsteiner test and Wassermann and Kahn reactions were negative. Cold agglutinins were absent. Serum bilirubin was $1.2 \mathrm{mg} / 100 \mathrm{ml}$.

He was diagnosed as suffering from paroxysmal nocturnal haemoglobinuria and as his haemoglobin level remained around $10 \mathrm{~g} / 100 \mathrm{ml}$, blood transfusion was withheld and he was discharged from hospital to be followed regularly as an out-patient.

He continued to be fairly well until 30 December 1959 when he was re-admitted as an emergency. For 2 days he had experienced severe central colicky abdominal pain which radiated into the right loin and was accompanied by vomiting. His temperature was $100^{\circ} \mathrm{F}$, he appeared pale and there was tenderness in the right iliac fossa but no palpable mass. Radiographs of his chest and abdomen revealed no abnormality. Over the succeeding few days his 


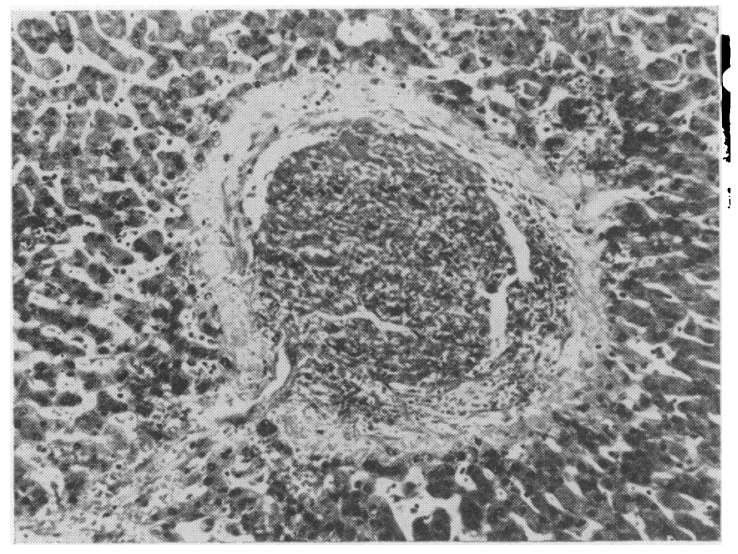

FIg. 1. Patient No. 1. Recent thrombus in hepatic vein ( $\times 24)$.

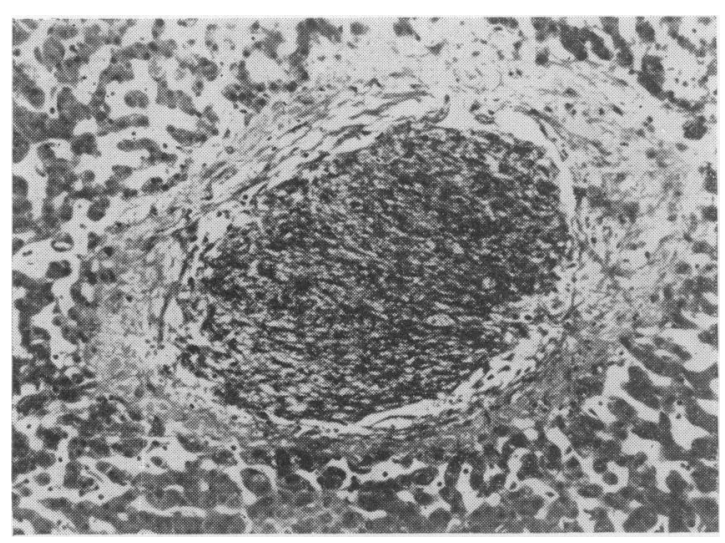

FIG. 2. Patient No. 1. Organized thrombus in hepatic vein $(\times 24)$.

abdomen swelled and his liver became enlarged and tender. Shifting dullness confirmed the presence of ascites.

Investigations: Blood: $\mathrm{Hb} 9 \cdot 8 \mathrm{~g} / 100 \mathrm{ml}$, reticulocytes $5 \%$ of RBC's. Liver function tests: serum bilirubin $1.4 \mathrm{mg} / 100 \mathrm{ml}$, zinc sulphate 6 units, thymol turbidity 5 units, thymol flocculation 0 , cephalin cholesterol + , alkaline phosphatase 37 i.u., SGO-T 54 i.u., SGP-T 39 i.u., serum proteins $6 \cdot 4$ $\mathrm{g} / 100 \mathrm{ml}$, albumen $3 \cdot 3 \mathrm{~g} / 100 \mathrm{ml}$, globulin $3 \cdot 1 \mathrm{~g} / 100$ $\mathrm{ml}$, electrophoresis, increase in gamma globulin, urine: bilirubin slightly positive, urobilin present in excess of normal, blood pigments absent.

Because of the rapid development of ascites and the tender enlargement of the liver, a diagnosis of hepatic vein thrombosis was seriously considered, and on 14 January 1960 a laparotomy was performed by $\mathrm{Mr} \mathrm{D}$. B. Leaming who reported as follows:

'The abdomen was opened through an upper right paramedian incision. A large amount of brown free fluid was present. The liver was enlarged and tense with a rounded edge. The spleen was enlarged two to three times normal and was hard and rather nodular. No other abnormality could be felt within the abdomen. A biopsy was taken from the left lobe of the liver.'

The ascitic fluid was sterile on bacteriological culture and contained red blood cells, lymphocytes, polymorphonuclear leucocytes and serosal cells.

Histology (Dr R. O. K. Schade): 'The architecture of the liver parenchyma is normal. The central veins show no abnormalities. In some of the lobules the sinusoids of the central portions are dilated and contain pools of blood. The most striking feature is the presence of thrombi within the larger veins. These are of varying age, some obviously very recent and others either undergoing organization or already completely organized. The picture is that of venoocclusive disease, compatible with the clinical condition of the Budd-Chiari syndrome.'

In due course, in an attempt to determine whether an anastomotic surgical procedure was feasible, further radiological studies were undertaken. A barium swallow demonstrated small oesophageal varices. A splenic venogram demonstrated the opaque medium in a network of splenic vessels but none entered the splenic or portal veins. This could have indicated either very high pressure in these veins, or actual thrombosis, although 6 weeks earlier they had been found to be patent at laparotomy. A hepatic venogram was attempted by cardiac catheter technique but an adequate demonstration was not obtained.

The patient's general condition rapidly deteriorated and further surgical measures were dismissed. Over the ensuing months ascites rapidly reaccumulated in spite of diuretic therapy and repeated paracenteses; jaundice supervened and a prominent collateral venous circulation developed on the abdominal wall and over the costal margin. Frequent blood transfusions were necessary to maintain his haemoglobin level. A trial of anticoagulant therapy with phenindione for several weeks was of little avail.

His last recorded admission to hospital for transfusion and paracentesis abdominis was on 11 October 1960 , and death occurred at his home soon after this; a necropsy was not performed.

\section{Patient No. 2}

A 63-year-old housewife was admitted to the Royal Victoria Infirmary on 4 November 1967. For the previous 2 years she had experienced recurrent attacks of jaundice accompanied by pain in the right hypochondrium at intervals of approximately 2 months. Each attack lasted for about 3 


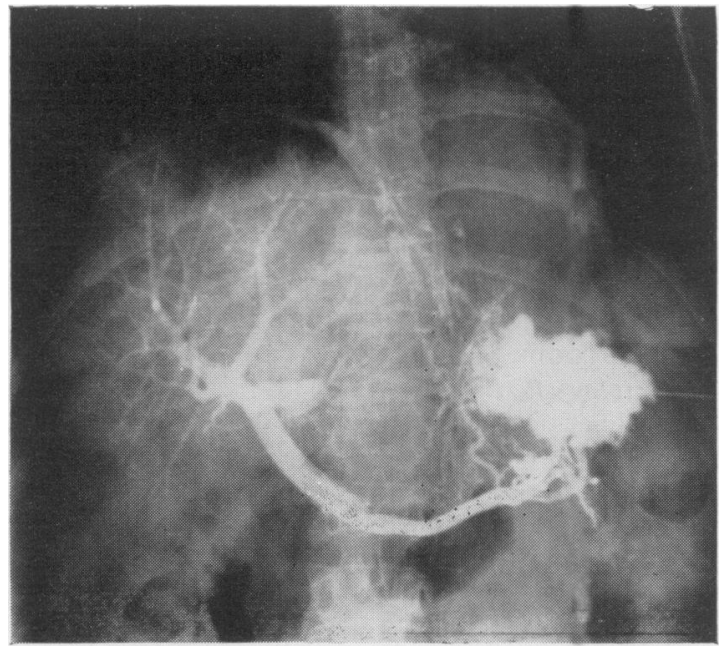

Fig. 3. Patient No. 2. Splenoportal venogram. Early film showing patent splenic and portal veins.

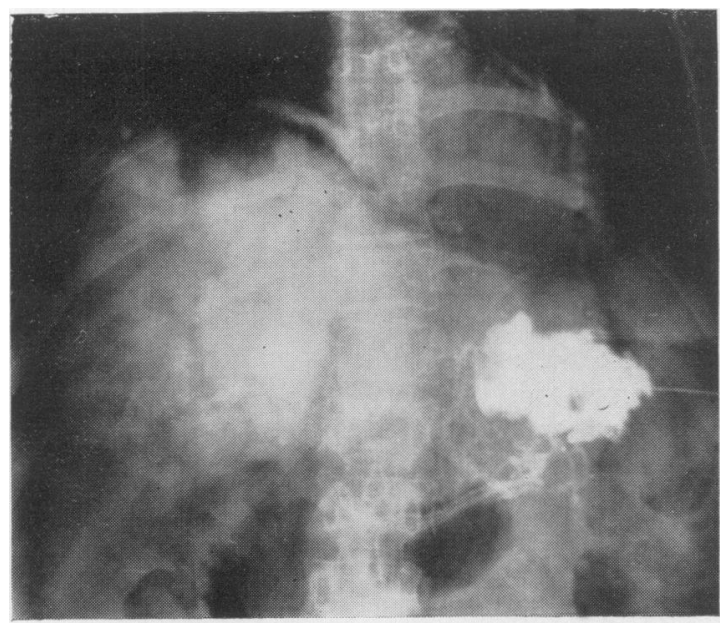

FIG. 4. Patient No. 2. Splenoportal venogram. Delayed film showing contrast retention in the liver after one minute.

weeks. She had noticed that her urine was dark brown in the morning on rising, but that her stools were of normal colour. In July 1967 she was admitted to Preston Hospital, North Shields, where no abnormal physical signs were demonstrable. Barium meal and barium enema examinations and cholecystography showed no abnormality. A laparotomy was undertaken and a cholecystectomy performed. The gall-bladder was described as showing signs of mild congestion and contained thick, semi-solid, almost black bile. The liver was noted to have a mottled appearance; no biopsy was taken.
Investigations: Following operation her haemoglobin fell to $9 \mathrm{~g} / 100 \mathrm{ml}$ and reticulocytes were $7 \%$ of RBCs. WBCs were $7000 / \mathrm{mm}^{3}$ with a normal differential count. Direct Coombs' test was negative, saline fragility of red cells was within normal limits and marrow films were reported as showing macronormoblastic erythropoiesis. Serum vitamin $B_{12}$ was $135 \mu \mu \mathrm{g} / \mathrm{ml}$ and serum folate $4.6 \mathrm{~m} \mu \mathrm{g} / \mathrm{ml}$. Serum bilirubin was $2.3 \mathrm{mg} / 100 \mathrm{ml}$ and lactic acid dehydrogenase was greater than 2000 units. She was given a blood transfusion and discharged to Eastbourne for convalescence.

While there, during August 1967, she developed ascites and was admitted to hospital for paracentesis. On her return home ascites rapidly reaccumulated and she was admitted again to Preston Hospital and treated with frusemide and spironolactone with some improvement. Further investigation showed a haemoglobin of $12.5 \mathrm{~g} / 100 \mathrm{ml}$ and a reticulocytosis of $7 \%$. Platelets were $37,000 / \mathrm{mm}^{3}$, WBCs $6600 / \mathrm{mm}^{3}$ and serum bilirubin $1.5 \mathrm{mg} / 100 \mathrm{ml}$.

At this stage she was transferred to the Royal Victoria Infirmary. She looked ill and wasted, was pale and slightly jaundiced and had numerous ecchymoses on her legs and a little ankle oedema. A fairly marked ascites was present and a firm irregular liver edge was palpable three fingers' breadths below the costal margin. There was no palpable splenic enlargement and no visible collateral venous circulation.

Investigations: Blood: $\mathrm{Hb} 11.0 \mathrm{~g} / 100 \mathrm{ml}$, reticulocytes $5.8 \%$, platelets $70,000 \mathrm{~mm}^{3}$, ESR $22 \mathrm{~mm}$ in $1 \mathrm{hr}$ (Westergren). Liver function tests: serum bilirubin $0.7 \mathrm{mg} / 100 \mathrm{ml}$, flocculation reaction negative, alkaline phosphatase 113 i.u., SGOT 22 i.u., lactic acid dehydrogenase 325 i.u., bromsulphthalein excretion $-15 \%$ remained in $45 \mathrm{~min}$. Serum protein $6.9 \mathrm{~g} / 100 \mathrm{ml}$, with normal electrophoretic pattern. Urine contained excess of urobilinogen but no bilirubin. Barium swallow showed a small oesophageal hiatus hernia but no evidence of varices.

An abdominal paracentesis produced clear strawcoloured fluid with a protein content of $4 \cdot 1 \mathrm{~g} / 100 \mathrm{ml}$ and no demonstrable malignant cells. A needle biopsy of the liver was reported as normal and a radioactive hepatogram using colloidal gold showed a diminished uptake over the right lobe.

A laparotomy was performed by $\mathrm{Mr} \mathrm{P}$. $\mathrm{H}$. Dickinson on 15 December 1967. Eight litres of ascitic fluid was evacuated and gross hepatomegaly was confirmed. The spleen was found to be twice the normal size and there were numerous distended and tortuous veins on the surface of the viscera. A biopsy of the liver was taken.

Histology (Dr J. Hart-Mercer): 'The histological appearances suggest the probability of hepatic vein thrombosis or Budd-Chiari disease. Some of the 
portal tracts have become enlarged and fibrosed but the brunt of the damage here is centrilobular. In the lobular centres the liver cells have largely disappeared and are replaced by distended sinusoids or haemorrhage. At the lobular periphery, on the other hand, the cells show nuclear activity. An occasional thick-walled vein is noted but none at this level is actually thrombosed.'

Following recovery from her operation, a splenic venogram was performed. The pressure in the spleen was $30 \mathrm{~cm}$ saline. The splenic and portal veins were freely patent and small gastric and oesophageal varices were demonstrated. The portal venous radicles appeared normal but the persistence of a dense heptogram for $1 \mathrm{~min}$ was thought to be compatible with hepatic vein thrombosis (Figs. 3 and 4).

Catheterization of the inferior vena cava was performed by Dr J. Muscat-Baron, via the right median vein, and the hepatic veins could not be entered. An inferior vena cavogram showed no retrograde flow into the hepatic veins, again suggesting thrombosis of these veins. Blood samples taken from the superior vena cava, and from the inferior vena cava above and below the entry of the hepatic veins, produced euglobulin lysis times of $100 \mathrm{hr}, 80 \mathrm{hr}$ and $100 \mathrm{hr}$ respectively. (Normal range $90-250 \mathrm{~min}$, Menon, 1968.)

Having reached a diagnosis of the Budd-Chiari syndrome, the presence of haemolytic anaemia and thrombocytopenia suggested to us the possibility of paroxysmal nocturnal haemoglobinuria in view of the association of the two conditions in our previous patient. A Ham test and sugar-water test (Hartmann \& Jenkins, 1966) were done and were both positive, confirming the diagnosis. Haemosiderin was present in the urine although haemoglobin was not demonstrated. Methaemalbumen was present in the serum.

She was treated with diuretics in the form of frusemide and spironolactone but required periodic admission to hospital for blood transfusion and for paracentesis abdominis.

Her last admission was on 5 August 1968 when she was found to have a gross ascites and umbilical hernia. Her haemoglobin was $12 \cdot 2 \mathrm{~g} / 100 \mathrm{ml}$ and reticulocytes were $3 \cdot 2 \%$ of RBCs. Platelets were $180,000 / \mathrm{mm}^{3}$. The response to diuretics and intravenous mannitol was poor and further paracentesis became necessary. Haemoglobinuria continued and she became progressively anaemic. Her general condition deteriorated and she complained of severe abdominal pain. Ultimately she became drowsy and confused and developed a detectable foetor hepaticus. Death occurred on 20 September 1968.

A necropsy was performed by Dr Nicholas Wright who reported thrombosis of all the main hepatic veins, mural thrombosis of the inferior vena cava, and old and recent thrombi in the intrahepatic veins. There was no thrombus in the extrahepatic portal system. There was enlargement of the spleen and change in the hepatic parenchyma characteristic of the Budd-Chiari syndrome. There was also basal bronchopneumonia.

\section{Discussion}

The Budd-Chiari syndrome has a varied aetiology but in the majority of reported cases no predisposing condition has been found. Parker (1959) reviewing 165 reports of this disorder, found an established primary condition in $30 \%$. Of these the predominant causes were polycythaemia vera, hypernephroma and malignant involvement of the inferior vena cava. Other haematological disorders as well as polycythaemia have been found to be associated with the Budd-Chiari syndrome, namely, sickle-cell anaemia and leukaemia (Palmer, 1954). The association with paroxysmal nocturnal haemoglobinuria ('Marchiafava-Micheli disease') was reported by Refvem \& Ytrehus in 1959 and we have been unable to find in the literature any further examples of this association. Their patient was a man of 30 who was admitted to hospital on a number of occasions with abdominal pain and was found to have enlargement of the liver and spleen and, subsequently, ascites. Increased haemolysis was shown by radioactive chromium studies and free haemoglobin was present in the serum. Splenectomy was performed. In due course haemoglobinuria was discovered and the Ham test was found to be positive. Further attacks of abdominal pain with pyrexia occurred and as these were considered to be thrombotic, anticoagulant treatment with dicoumarol was instituted. Deterioration was rapid and death occurred. At necropsy most of the hepatic veins were thrombosed and there was centrilobular congestion and liver cell atrophy in the central and middle zones. Numerous thrombi were found in the branches of the portal vein, and in the mesenteric, splenic and renal veins.

The clinical presentations differed markedly in our two patients. The first patient began with the symptoms of paroxysmal nocturnal haemoglobinuria which were quite classical and offered no difficulty in diagnosis. Haemoglobin and haemosiderin were present in the urine, free haemoglobin and methaemalbumen were demonstrable in the plasma and the Ham test was positive. The complication of hepatic vein thrombosis was an acute episode leading to his admission to hospital as an emergency. Hepatomegaly and ascites developed rapidly and the diagnosis was made by liver biopsy at laparotomy. Our second patient presented with recurrent abdominal pain, persisting ascites and evidence of haemolytic anaemia, and in this respect resembled the patient of Refvem \& Ytrehus. Again 
the diagnosis of hepatic vein thrombosis was made by liver biopsy at laparotomy and the previous experience with our first patient prompted us to look for paroxysmal nocturnal haemoglobinuria as an explanation for her haemolytic anaemia and thrombocytopenia. The clinical course, however, was similar in each, with progressive deterioration, recurrent ascites and anaemia, and death approximately 10 months after laparotomy.

Diagnosis during life of the Budd-Chiari syndrome depends upon histological section of a biopsy specimen of the liver obtained at laparotomy when other causes for hepatomegaly and ascites can be excluded. Parker (1959) summarizes the changes as sinusoidal congestion with centrilobular atrophy or necrosis, regeneration in the periportal regions occasionally being found. These were, in fact, the changes reported in our second patient, although no actual thrombi were seen in the hepatic centrilobular veins in the section examined. In our first patient thrombi were apparent. Additional evidence was forthcoming from splenic and hepatic venography. In our first patient no dye left the spleen, while in the second patient it persisted for some time in the liver, presumably due to the impaired drainage into the inferior vena cava.

Thromboses are a common complication of paroxysmal nocturnal haemoglobinuria and as mentioned earlier, have been reported at necropsy in the hepatic and portal veins. Crosby (1953), in a review of fifty-one recorded patients, found that thromboses occurred in twenty-four, the veins involved including the portal, hepatic and mesenteric, the veins of the arms and legs, and the haemorrhoidal and penile veins. The cause of the thrombotic tendency has been the subject of much speculation and has been well reviewed by Dacie (1967). In 1950 Crosby \& Dameshek could detect no abnormality of coagulation in vitro and assumed that enhanced platelet sensitivity to the haemolytic factor gave rise to increased aggregation and the development of platelet thrombi. They also suggested an association between the haemolytic mechanism in paroxysmal nocturnal haemoglobinuria and the blood coagulation system, in that haemolysis was stimulated by small amounts of thrombin.

It is likely that a hypercoagulable state exists in paroxysmal nocturnal haemoglobinuria. Bradlow (1961) showed that abnormally large amounts of thromboplastic material were released by the red cells in this condition and Newcomb \& Gardner (1963) considered that thrombin generation was demonstrably increased. The further possibility that impaired fibrinolysis might contribute to the thrombotic tendency was suggested by the markedly prolonged euglobulin lysis time in our second patient.

\section{Acknowledgments}

We are grateful to Dr R. O. K. Schade, Dr J. Hart-Mercer and Dr Nicholas Wright for the pathological reports on these two patients, to Dr J. Muscat-Baron for catheterization studies of the second patient, and to Dr I. S. Menon for performing the euglobulin lysis times. We are also grateful to Dr R. Paley, Consultant Physician, Preston Hospital, North Shields, for referring the second patient, and to Dr P. M. Hacking for performing splenic venography.

\section{References}

BergmarK, G. (1931) Ein Fall von Intermittierender Kryptogener Hämoglobinurie. Acta Medica Scandinavica, 77, 224.

BRADLOW, B.A. (1961) Liberation of material with plateletlike coagulant properties from intact red cells and particularly from reticulocytes. British Journal of Haematology, 7, 476.

CROSBY, W.H. (1953) Paroxysmal nocturnal haemoglobinuria. Relation of the clinical manifestations to underlying pathogenic mechanisms. Blood, 8, 769.

Crosby, W.H. \& Dameshek, W. (1950) Paroxysmal nocturnal haemoglobinuria. The mechanism of haemolysis and its relation to the coagulation mechanism. Blood, $\mathbf{5}$, 822.

DACIE, J.V. (1967) The Haemolytic Anaemias. 2nd Ed. Churchill, London.

Ellenhorn, J.J., Feigenbaum, L.Z., Plumhof, C. \& MetTIER, S.R. (1951) Paroxysmal nocturnal haemoglobinuria with chronic haemolytic anaemia. Archives of Internal Medicine, 87, 869.

HAM, G.C. \& HoRACK, H.M. (1941) Chronic haemolytic anaemia with paroxysmal nocturnal haemoglobinuria. Archives of Internal Medicine, 67, 735.

HaRtmanN, R.C. \& Jenkins, D.E. (1966) The sugar-water test for paroxysmal nocturnal haemoglobinuria. New England Journal of Medicine, 275, 155.

Heitzman, E.J., Campbell, J.S. \& Stefanini, M. (1953) Paroxysmal nocturnal haemoglobinuria with haemosiderin nephrosis. American Journal of Clinical Pathology, 23, 975.

MenON, I.S. (1968) Fibrinolytic activity in the blood of ninety-nine healthy young British, African and Asian subjects. Laboratory Practice, 17, 194.

Merliss, R.R. (1952) Paroxysmal nocturnal haemoglobinuria. A clinicopathological correlation. New England Journal of Medicine, 246, 642.

Newcomb, T.F. \& GARDNER, F.H. (1963) Thrombin generation in paroxysmal nocturnal haemoglobinuria. British Journal of Haematology, 9, 84.

PARKER, R.G.F. (1959) Occlusion of the hepatic veins in man. Medicine, 38, 369.

RefVem, O. \& YTRehus, K. (1959) Budd-Chiari syndrome in Marchiafava-Micheli disease. Journal of the Oslo City Hospitals, 9, 207.

Scotr, R.B., RobB-Smith, A.H.T. \& Scowen, E.F. (1938) The Marchiafava-Micheli syndrome of nocturnal haemoglobinuria with haemolytic anaemia. Quarterly Journal of Medicine, 7, 95 . 